\title{
Research on the whole plan of cultivating double creative undergraduates of tutorial system
}

\author{
Lili Zhou ${ }^{1, a,{ }^{*}, \text { Mingming Xing }}{ }^{1, b,{ }^{*}}$ \\ ${ }^{1}$ School of Chemistry \& Chemical Engineering, Linyi University, Shandong Province, China \\ ${ }^{1}$ School of Mechanical \& Vehicle Engineering, Linyi University, Shandong Province, China \\ azlllilyjoe2009@163.com, bxingmingming2009@126.com \\ ${ }^{*}$ Corresponding author
}

Keywords: Talents training, Tutorial system, Innovation and entrepreneurship education.

\begin{abstract}
According to the shortcoming of talents training pattern of Innovation and Entrepreneurship Education (IAEE) in undergraduate instructional system, and considering the limitations of IAEE with tutorial system, the whole plan and research method of IAEE for undergraduate training are proposed in the tutorial system. At the same time, the research framework of high-level, practical and integrated talents are presented for the needs of economic construction and talents in enterprise or business. This research will establish the foundation for construction and generalization of cultivating double creative undergraduates of tutorial system.
\end{abstract}

\section{Introduction}

In recent years, the undergraduate education and reform are explored in major universities. New research shows that IAEE is a new teaching model for meeting the challenge of undergraduate education [1]. The survey result of undergraduate tutorial system is shown in Fuzhou University [2]. The tutorial system is hardly implemented smoothly, and some problems are exposed. For example, the teacher's responsibility is not clear, the direction and content is more unitization; Lack of reasonable advisor work evaluation system. To sum up, there are some problems in Undergraduates Tutorial System like shortage of tutors, unclear definition and formalism. Reforms must be done, which must lies in the development of independent thinking, the focus on instructional system, instruction through the whole process, tutor qualification and enhancement of tutorial system [3]. Guo Yong, a professor in Tsinghua University, indicates that when Chinese universities tried to pursue the college system without overall general education, they might meet great difficulties. Actually, Chinese universities needn't copy the college system. What's more important was to put more emphasis on general education in undergraduate education [4]. Effective measures to standardize the management of undergraduate scientific research are proposed by Zhang through the analysis of the development opportunities and operation of the undergraduate research guide system. The effective measures are as follows: to set up and assign the principle of the supervisor's responsibility, establish relevant evaluation and incentive mechanism, and attach importance to strengthen the management of the undergraduate research and innovation process [5]. Jiang started from the connotation of tutorial system, analyzes the tutorial system in our country development present situation and the existing problems. Furthermore, the subsection undergraduate training mode combining the tutorial system and credit system is constructed, and its implementation requirements are put forward [6]. With respect to the development of undergraduate tutorial system, Zhou combines the development trend of China's higher education, and puts forward the breakthrough of the tutorial system, which is centered on the construction of university academic guidance center [7]. At the same time, the development course and the present situation of undergraduate tutor system of our country are analyzed by $\mathrm{Ma}$, and the development characteristics is summarized according to the educational concept and connotation of undergraduate tutor system of Oxford [8]. In order to provide references for reform and development of IAEE, the education mechanism, pathway and model of IAEE in 
undergraduate instructional system are presented [9]. The significance and problem of IAEE are given by Li. And the education platform of IAEE in undergraduate instructional system is explored with the practice of IAEE for Shandong University of Science and Technology [10].

In the international environment of industry 4.0, industry intent and Made in China 2025, the shortcoming of talents training pattern of IAEE in undergraduate instructional system is considered, and the limitations of IAEE with tutorial system is also analyzed. The whole plan and research method of IAEE Under undergraduate's tutorial system are proposed in the tutorial system. The whole plan is made of some parts, such as the improvement of education concept, determination of talents educating target, perfection of teaching model and method and the construction of quality assessment system management system of IAEE. The research framework of high-level, practical and integrated talents is presented for the needs of economic construction and talents in enterprise or business.

\section{Analysis of whole research plan}

Firstly, the developing trend of IAEE is given, and the influence of talent training pattern of IAEE is analyzed. Secondly, the educational concept of IAEE is improved, and the goal of IAEE is established. The frame diagram of whole plan is shown in Fig.1.

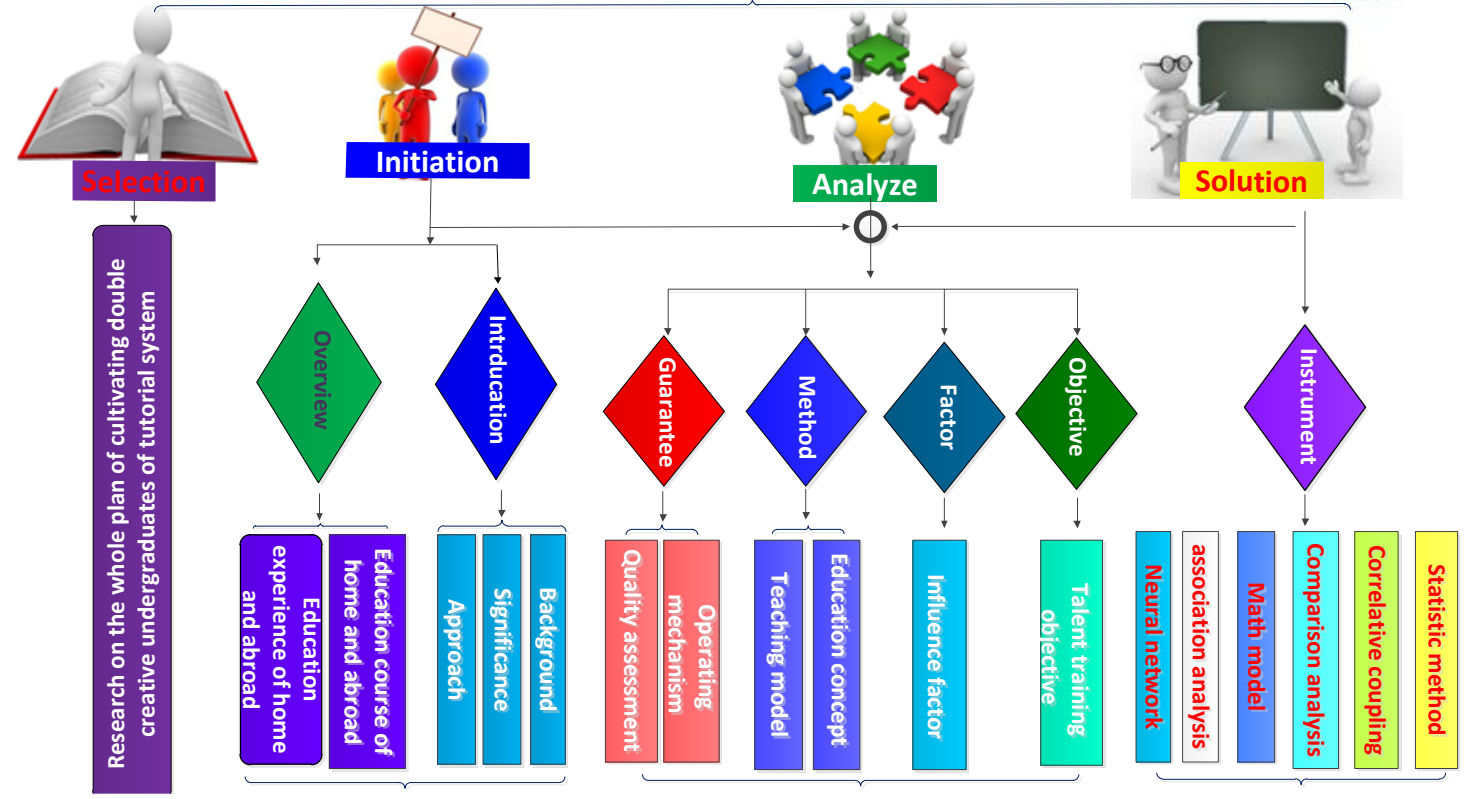

Fig. 1. The frame diagram of whole plan for IAEE

\subsection{Development and trend of IAEE under undergraduate tutorial system}

The development course and experience of international education of IAEE are summarized. The situation of Chinese IAEE is discussed since 1970s. The difference of IAEE for undergraduate training of home and abroad is analyzed. This research lays the theory foundation for the design, construction and implement of IAEE for undergraduate training.

\subsection{Affecting factors of IAEE under undergraduate tutorial system}

The interest correlation of IAEE under undergraduate tutorial system is analyzed. Considering the factors of student option, importance perception of IAEE and resource allocation of IAEE, the structural equation model is built. With the model, the impact factors are analyzed, which shows key impact factor of IAEE under undergraduate tutoring system.

\subsection{Education objection and idea of IAEE under undergraduate tutoring system}

The scientific idea is necessary for education system. The traditional education concepts that impart knowledge as the center and Intentional unintentional restraining the traditional education concept that kills students' innovative spirit should be reformed. The modern education idea of focusing on 
cultivate students' innovative spirit and basic qualities of entrepreneurship is the precondition of conform to the 2025 industrial revolution made in China and to carry out IAEE undergraduate education. The concept of IAEE undergraduate culture under the guidance of science is necessary to be established. IAEE of undergraduate education under the tutorial system should be explored and the target of IAEE undergraduate education should be established.

\subsection{Training mechanism of IAEE under undergraduate tutoring system}

Based on the long-term goal of building IAEE model groups, analysising project of IAEE, and standing on the international stage, it is necessary to build educational management system of IAEE under undergraduate tutoring system. Synthesizing extra-curricular activities should be carried out actively, guidance mechanism of tutoring system should be played fully, and tissue support of point, line and surface should be provided, so that education service system of IAEE under undergraduate tutoring system can be perfected. Improving incentive measures contains mental reward as while as material reward to ensure the timeliness and sustainability of the incentive process and to improve the internal incentive system of IAEE in undergraduate.

\subsection{Talents development target of IAEE under undergraduate tutoring system}

Students' value orientation, code of conduct, ideology, learning norms and motivation must be actively guided in the process of talent cultivation. To help students build their ideal and career development goals, learn to choose and plan. The students are guided gradually with their own way to gradually realize their career aspirations and goals. The target characteristic of IAEE contains two aspects one is general characteristics and the other is industry characteristics. General characteristics contain six aspects. First of all, IAEE of undergraduate should have a solid knowledge base and a complete knowledge structure. Secondly, IAEE of undergraduate should have good independent study, relearning habits and ability. Thirdly, IAEE of undergraduate should have typical innovation and entrepreneurial consciousness and perseverance spirit and will. Fourthly, IAEE of undergraduate should have keen insight and unique way of thinking, good at judging and grasping opportunities. Fifthly, IAEE of undergraduate should have excellent ability of innovation, practice, implementation and development. Sixthly, IAEE of undergraduate should have excellent team spirit, cooperative ability and social competitiveness. Industry characteristics contain two aspects. Firstly, IAEE of undergraduate should be systematically master the professional knowledge, with innovative features and entrepreneurial potential. Secondly, IAEE of undergraduate should have basic ability of product design and development and management. Be able to work in the fields of design and manufacturing, scientific and technological development, application research, operation management and operation sales in the field of production.

\subsection{Teaching mode and method of IAEE under undergraduate tutoring system}

The practice teaching model of IAEE under undergraduate tutoring system is built. In detail, the ability variation of practice teaching system is managed. The teaching contents are optimized. The scientific literacy of each major is enhanced. At the same time, the teaching method of IAEE is changed as follows. The total innovation of patterns, artifice, contents and process of teaching is promoted with higher educational ideas. In order to simulate student interest and curiosity, the knowledge-oriented, combined with theory and practice, high coupling of tutor and traditional courses and the stage of social practice are used.

\subsection{Educational quality assessment of IAEE under undergraduate tutoring system}

The evaluation body and way of educational quality of IAEE are selected with the evaluation method of teaching staff, students and course system. IAEE is a systematic educational project, containing the government, university and society. There are many influence factors, for example, educational and teaching, practice platform, teaching staff and social support. Therefore, the education content of IAEE is necessary analyzed, some characteristics are also analyzed, such as objective oriented, system coordination, scientific, dynamics and flexibility, and so on. The index designing and evaluation 
method are determined with individual student, family background and school environment. Finally, the educational quality assessment system of IAEE is designed from the government aspect, college aspect, student and society aspect.

\section{Analysis of research method}

(1) Analyze method of literature statistical

The literatures of IAEE at home and abroad are collected. The leading-edge academic research is followed. Some problems of IAEE are found, which lays the foundation for IAEE under undergraduate tutoring system.

(2) Analyze method of correlative coupling

The coupling analysis of innovative education and entrepreneurial education is built. The correlative mathematical model is built and the coupling factors are found and analyzed.

(3) Comparison Analysis method

The training mode of tutorial system and educational theory and practices are researched, the difference of IAEE at home and abroad is found. The development of IAEE in every age is analyzed, the development process and future trends of IAEE are found.

(4) Analyze method of structural equation model

Based on the structural equation model, the key affecting factors of IAEE are analyzed with LISREL software, which plays a directive role in building undergraduate training system of IAEE.

(5) Correlation analysis of empirical study and case study

With the questionnaires and surveys, the development and existing problem of IAEE is found and the objective data from entrepreneur of university is got. The typical cases are analyzed for energetically advance process of IAEE under undergraduate tutoring system.

(6) Analyze method of BP artificial neural networks

The model of artificial neural networks is comprehensive evaluation model closer to human experts thinking with self- learning of the neural networks, self-adaptive ability and fault tolerant. In this research, the analyze method of BP artificial neural networks is used for educational quality evaluation of IAEE.

\section{Summary}

With the wave of industrial revolution of Made in China 2025, the whole plan and research method of IAEE for undergraduate training are proposed in the tutorial system on the basis of the shortcoming of talents training pattern of IAEE and limitations of IAEE. Firstly, the development and developing trends of IAEE are analyzed. And the affecting factors of IAEE under undergraduate tutoring system are found. Secondly, the goal of talents training is made with new educational ideas, educational model and method of IAEE. Finally, the educational quality evaluation of IAEE is given to form a closed loop control system. The research methods are given based on the correlative coupling method, contrastive analysis method, structural equation model, empirical study and case study and BP artificial neural networks. The research results will guide the direction of IAEE under undergraduate tutoring system, and lay the foundation for diversified education.

\section{Acknowledgement}

This research was financially supported by the Starting Foundation for Linyi social science research project (Grant No. 2017LX250), Soft science research project of Shandong Province (Grant No. 2017RKA13008), Initial funding of Linyi University (Grant NO. LYDX2016BS032), Innovation and entrepreneurship fund of national project (Grant NO. 201710452066) and Shandong provincial natural science fund (Grant No. ZR2017LEE002). 


\section{References}

[1] M Xing, L Zhou, A Novel Teaching Mode of Mechanical Engineering Based on Compatibility Mode of Guidance and Giving Lecture, International Conference on Social Science and Higher Education, pp.9-12, 2016.

[2] J Wang, Investigation and Analysis of Undergraduate Tutorial System Implementation Status-A Case Study of Fuzhou University, Forum on Contemporary Education,vol.1,pp. 41-45,2012.

[3] R Yan, The Significance and Reform of Undergraduates Tutorial System, Research in Educational Development, vol. 21, pp. 73-76, 2013.

[4] Y Guo, The Organizational Model of Undergraduate Education: From Harvard University, Journal of Higher Education, vol.37, pp. 64-73, 2016.

[5] S Zhang, H Zhang, The consideration for implementation and administration of undergraduate's tutorial system, Continue Education Research, vol.8, pp. 83-85, 2014. (Chinese)

[6] Y Jiang, Y Li, The question and optimization of training model of undergraduate's tutorial system, Heilongjiang Education (Higher Education Research \& Appraisal), vol. 7, pp. 56-57. (Chinese) 2014

[7] J Zhou, Study on undergraduate tutoring- Taking Liaoning Normal University as An Example, Liaoning Normal University, 2015. (Chinese)

[8] J Ma, The Undergraduate Tutorial System reform of Chinese universities-in the Perspective of Oxford Tutorial System localization, East China University of Science and Technology, 2016. (Chinese)

[9] H Zhang, A Research on Innovation and Entrepreneurship Education in Colleges: Mechanism, Path and Pattern, Journal of National Academy of Education Administration, vol. 10, pp. 28-32, 2014.

[10] C Li, W Zhang, J Li, The construction and implementation of innovation and entrepreneurship education for engineering institutes, Heilongjiang Researches on Higher Education, vol. 4, pp. 97-99, 2014. (Chinese) 